Original research article

\title{
The effects of physiotherapy with PNF concept on gait and balance of patients with Huntington's disease - pilot study
}

\author{
Elżbieta Mirek $^{a, c, *}$, Magdalena Filip ${ }^{a, c}$, Krzysztof Banaszkiewicz ${ }^{c}$, \\ Monika Rudzińska ${ }^{d}$, Jadwiga Szymura ${ }^{a}$, Szymon Pasiut ${ }^{a}$, Joanna Stożek ${ }^{a}$, \\ Andrzej Szczudlik ${ }^{b}$ \\ a Department of Rehabilitation in Neurology and Psychiatry, University School of Education, Kraków, Poland \\ ${ }^{\mathrm{b}}$ Department of Neurology, Jagiellonian University Medical College in Cracow, Kraków, Poland \\ ${ }^{\mathrm{c}}$ Department of Neurology and Neurorehabilitation, John Paul's II Hospital, Kraków, Poland \\ ${ }^{\mathrm{d}}$ Department of Neurology, Medical University of Silesia, Katowice, Poland
}

\section{A R T I C L E I N F O}

Article history:

Received 3 June 2015

Accepted 3 September 2015

Available online 15 September 2015

Keywords:

Huntington's disease

Gait

Physiotherapy

\begin{abstract}
A B S T R A C T
Background and purpose: Huntington's disease (HD) is a neurodegenerative, progressive disorder of the central nervous system which causes significant gait and balance disturbances. This is a pilot study which aims to determine the effects of a physiotherapy programme with use of Proprioceptive Neuromuscular Facilitation (PNF) on gait and balance in HD patients.

Material and methods: $30 \mathrm{HD}$ patients aged 21-60 with genetically confirmed diagnosis participated in the study. Participants followed a 3-week-long PNF-based physiotherapy programme. Gait and balance were evaluated twice in each participant: first at baseline and then after the course of physiotherapy. The following methods were used for gait disturbances: Tinetti Gait Assessment Tool, Up and Go Test, Timed Walking Tests for $10 \mathrm{~m}$ and $20 \mathrm{~m}$ (TWT10m, TWT20m). Balance was assessed with use of Berg Balance Scale, Pastor Test and Functional Reach Test.

Results: There was a significant improvement in all measures of balance and gait.

Conclusion: PNF-based physiotherapy is effective and safe in HD patients.
\end{abstract}

(C) 2015 Polish Neurological Society. Published by Elsevier Sp. z o.o. All rights reserved.

\section{Introduction}

Huntington's disease (HD) is a neurodegenerative, progressive disorder of the central nervous system inherited in an autosomal dominant trait. HD is clinically manifested by cognitive impairment, behavioural signs and a variety of movement disorders including chorea, dystonia, ataxia or parkinsonism [1]. All of these movement disorders cause gait disturbances and increase the risk of falls [2]. The typical

\footnotetext{
* Corresponding author at: University School of Physical Education in Cracow, Al. Jana Pawła II 78, Kraków, Poland. Tel.: +48 695327424.

E-mail address: mirek.ela@wp.pl (E. Mirek).

http://dx.doi.org/10.1016/j.pjnns.2015.09.002

0028-3843/ (C) 2015 Polish Neurological Society. Published by Elsevier Sp. z o.o. All rights reserved.
} 
features of gait disturbances in HD are as follows: reduction of gait velocity and frequency, extended gait cycle, prolonged double support phase, shortening of the step length, and large variability in the length and height of steps [3-6]. The mechanism of gait disturbances in HD is still unknown. Involuntary movements seem to play minor role and their treatment does not improve gait [6]. Another symptom of HD is balance disturbances. Recent study shows that HD patients produce more sway than control subjects during standing. Furthermore, they have slower reaction and more falls while unexpected or sudden rotation of the support surface [7]. Gait and balance dysfunction occur in an early stage of the disease [8]. So far there have been several papers on gait and balance disorder in Huntington disease, most of them included small numbers of participants and showed positive results of rehabilitation and physical therapy [9-11] and none of them used a special physiotherapeutic technique. There is no established pharmacotherapy of gait or balance disturbances in HD therefore physiotherapy appears encouraging therapeutic option $[12,13]$. Physiotherapy techniques constitute the primary treatment approach in the management of gait and balance disturbances irrespectively of the cause. Proprioceptive Neuromuscular Facilitation (PNF) is one of widely used methods of physiotherapy. It is a complex technique of neuromuscular re-education [14] which is based on the maximal stimulation of proprioceptive and external (touch, verbal, visual) receptors aiming at activation of impaired structures of the nervous system. PNF was previously found effective in the treatment of gait and balance disturbances in Parkinson's disease (PD) $[15,16]$. This study aims to determine the effects of the PNF physiotherapy programme on gait and balance of patients with Huntington's disease.

\section{Material and methods}

The study was conducted between October 2009 and May 2010 according to the Declaration of Helsinki and was approved by the Local Ethical Committee. The inclusion criteria were as follows: mutation in the HTT gene in genetic testing, HD motor manifestation (chorea, dystonia, and/or gait disturbances) at baseline neurological examination, stable pharmacotherapy for at least one month prior to inclusion, the patient's informed consent to participate in the study. The exclusion criteria were: severe disability (stage 5 of the Shoulson and Fahn scale [17]), significant cognitive dysfunction or psychiatric symptoms (e.g. aggression, psychosis, depression) that prevented effective cooperation between the patient and physiotherapist, any orthopaedic condition (e.g. fractures, sprains) impeding movement. Participation in the study was offered to 34 consecutive HD patients admitted to the Department of Neurology, Outpatients Clinic. Two patients refused to take part in the study. The remaining 32 patients were included in the study, followed baseline examination and entered the physiotherapy programme. Two patients were excluded during the course of physiotherapy because of an outburst of impulsive behaviour. The characteristics of the study group are shown in Table 1. The intervention was a 3-week-long intensive physiotherapy programme. Physiotherapy was provided five days a week (15 sessions). During each
Table 1 - Characteristics of the study group.

\begin{tabular}{lccc} 
Patients & Mean & $\begin{array}{c}\text { Standard } \\
\text { deviation }\end{array}$ & Range \\
\hline Age (years) & 43.4 & 13.8 & $20-60$ \\
Number of CAG repetitions & 46.6 & 6.0 & $40-62$ \\
Disease duration (years) & 7.0 & 5.8 & $2-10$ \\
UHDRS cognitive & 123.9 & 43.31 & $10-186$ \\
UHDRS motor & 40.8 & 20.0 & $10-78$ \\
UHDRS functional assessment & 17.6 & 4.6 & $7-25$ \\
UHDRS independence scale & 76.67 & 13.2 & $50-100$ \\
TFC & 7.7 & 3.1 & $3-13$ \\
\hline
\end{tabular}

UHDRS - unified Huntington's disease rating scale; TFC - total functional capacity.

session the treating physiotherapist applied all the main techniques and principles of facilitation (e.g. slow approximation, timing for emphasis, bilateral reciprocal patterns) according to the PNF concept and used mainly the closed kinematic chains. Each session was 90 min long and consisted of three parts:

- introductory part (10 min) which included: warm-up, education of a correct body awareness and respiratory pattern, main part (70 min) which included: improvement of balance reactions, mat activities (rolling/prone on elbows/bridging/ side sitting/quadruped/kneeling/half-kneeling/standing), exercises in a sitting position (rocking/scooting), gait training (weight shifting/one leg standing/walking forward, backward, sideways/braiding),

- end part (10 min) which included relaxation techniques.

Pharmacotherapy was not changed during the study period. Gait and balance were evaluated twice in each participant: first at baseline and then immediately after the completion of the physiotherapy programme. The following methods were used for gait assessment: Timed Walking Test for $10 \mathrm{~m}$ (TWT10m) and Timed Walking Test for $20 \mathrm{~m}$ (TWT20m) [18,19], Up and Go Test (TUG) [20], Tinetti Gait Assessment Tool [21]. Balance was assessed with use of the Functional Reach Test (FRT) [22], Berg Balance Scale (BBS) [7] and Pastor Test [23]. Statistical analysis was done in the group of 30 patients who completed the course of physiotherapy and final examination. The analysis was performed using STATISTICA $^{\circledR} 9$ Statsoft. The non-parametric Wilcoxon test (matched pairs) was used. For correlation analysis Spearman's rank correlation coefficient was used.

\section{Results}

The improvement of static and dynamic balance was seen in a clinical scale (BBS) as well as in anticipatory balance tests (FRT, Pastor Test). The improvement of gait was significant in all tests. Gait and balance improvement seem to be higher in patients with more advanced gait disturbances. Unwanted effects of PNF were not identified. The two patients who were excluded from the study because of behavioural disturbances had had episodes of impulsive behaviours in the past, therefore we do not regard behavioural outbursts as an 
adverse event of PNF. The mean values of gait and balance measures before and after the course of physiotherapy as well as the mean difference are presented in Table 2.

\section{Discussion}

Previous studies show that rehabilitation (physiotherapy, occupational therapy, speech therapy) appears effective in the improvement of gait, balance, mobility and physical capability in HD and enhances patients independence $[10,24,25]$. The efficacy of physiotherapy alone was evaluated in a single study by Bohlen in $12 \mathrm{HD}$ patients. The patients were provided physiotherapy twice-weekly over 6 weeks. Significant improvements after physiotherapy were seen in TUG and BBS [11]. Improvement of motor disturbances after various antidopaminergic drugs is known in HD. However, there is sparse data in the literature on pharmacotherapy of gait and balance disturbances [26]. As compared to the data on the efficacy of PNF in PD patients, the improvement in gait and balance in our HD sample is rather small [15]. The possible explanation for the remarkably lower efficacy of PNF may be the cognitive impairment and behavioural disturbances of the HD patients. Although patients with severe dementia were excluded, the executive dysfunction of the participants might have affected therapy. Nevertheless physiotherapy of patients with cognitive impairment is possible and may be effective as shown in a study in Alzheimer's disease [27]. Another potentially confounding factor affecting treatment is behavioural disturbances. Apathy defined as lack of motivation seems to be the most common and troublesome behavioural symptom in HD [28]. Neither cognitive dysfunction nor behavioural disturbances were analysed as confounders of PNF efficacy in the present study.

The assessment of the efficacy of any therapeutic intervention is an extremely important part of its development and implementation. We have identified three groups of methods that may be applied to formal efficacy assessment: global functional scales or specific scales for gait, posture or neurologic signs assessment (e.g. TFC, UHDRS, BBS), functional tests (e.g. FRT, TWT10m) or instrumental methods, e.g. 3-D gait analysis. So far, none of the mentioned methods has been regarded as a gold standard of gait or balance assessment. The methods of gait and balance assessment applied in this study provide reliable and multidimensional information on gait and balance disturbances [1] and have been previously used in the assessment of a therapeutic interventions on gait or balance $[29,30]$.

Some limitations of the present study should be raised. First, the sample was small, thus it was not possible to stratify the results to disease severity, cognitive impairment, behavioural disturbances or drug allocation. Second, the sample was quite inhomogeneous in terms of the severity of symptoms and baseline measures of gait and balance. Another weakness of the study was lack of a delayed assessment of gait and balance following the final assessment. However, taking into account the study by Zinzi et al., who showed that there is a continuous effect of rehabilitation in HD after two years [10], we believe that PNF may also provide an unfading effect.

It is a matter of debate whether use of a protocol with a no-physiotherapy control group provides any additional information. We assume that the prerequisite of stable pharmacological treatment throughout the study and one month prior to inclusion excludes confounding effects of medication on the results of the study.

The efficacy of PNF should now be estimated in a group of early stage HD patients, and long-term effects should also be evaluated. Further research is also needed to predict the best responders to this method and compare PNF with other physiotherapeutic methods and pharmacologic therapy.

Table 2 - Descriptive statistics for measurements before and after PNF therapy.

\begin{tabular}{|c|c|c|c|c|c|c|c|c|c|}
\hline Test & & $\mathrm{Me}$ & $\mathrm{Q}_{1}$ & $\mathrm{Q}_{3}$ & Mean (range) & $\begin{array}{l}\text { Standard } \\
\text { deviation }\end{array}$ & $\begin{array}{l}\text { Mean } \\
\text { difference } \\
\text { (range) }\end{array}$ & $\begin{array}{c}\text { Standard } \\
\text { deviation of } \\
\text { difference }\end{array}$ & $p$-Value \\
\hline \multirow[t]{2}{*}{ Berg Balance Scale (score) } & BA & 50 & 43 & 53 & $46.9(19.0-30.0)$ & 8.6 & & & \\
\hline & FA & 52.5 & 50.0 & 56.0 & $52.5(38.0-56.0)$ & 5.3 & $-5.6(-20-0)$ & 5.7 & 0.000008 \\
\hline \multirow[t]{2}{*}{ Pastor Test (score) } & BA & 2.5 & 2.0 & 3.0 & $2.5(1-4)$ & 1.0 & & & \\
\hline & FA & 1.0 & 1.0 & 2.0 & $1.5(1-4)$ & 0.8 & $1.0(0.0-3)$ & 0.8 & 0.000040 \\
\hline \multirow[t]{2}{*}{ Functional Reach Test (cm) } & BA & 25.0 & 21.0 & 32.0 & $25.6(0.0-46.0)$ & 10.9 & & & \\
\hline & FA & 32.0 & 28.0 & 42.0 & $34.1(14.0-52.0)$ & 9.5 & $-9.4(-27.0-0.0)$ & 7.3 & 0.000006 \\
\hline \multirow{2}{*}{$\begin{array}{l}\text { Tinetti Gait Assessment } \\
\text { Tool (score) }\end{array}$} & BA & 8.0 & 5.0 & 10.0 & $7.8(2-13)$ & 2.9 & & & \\
\hline & FA & 11.0 & 10.0 & 13.0 & $11.1(8-13)$ & 1.8 & $-3.3(-9-0)$ & 2.1 & 0.000003 \\
\hline \multirow[t]{2}{*}{ Up and Go Test (s) } & BA & 9.1 & 7.5 & 11.3 & $9.5(6.0-14.4)$ & 2.4 & & & \\
\hline & FA & 7.0 & 6.4 & 8.6 & $7.7(5.5-11.9)$ & 1.7 & $1.8(-2.1-5.0)$ & 1.8 & 0.000021 \\
\hline \multirow[t]{2}{*}{ Timed Walking Test $10 \mathrm{~m}(\mathrm{~s})$} & BA & 7.9 & 7.2 & 9.2 & $8.3(6.1-13.9)$ & 1.6 & & & \\
\hline & FA & 7.6 & 6.5 & 8.3 & $7.6(5.3-11.5)$ & 1.5 & $0.7(-1.8-4.3)$ & 1.2 & 0.002415 \\
\hline \multirow[t]{2}{*}{ Timed Walking Test $20 \mathrm{~m}$ (s) } & BA & 15.9 & 14.7 & 20.2 & $17.2(12.5-26.6)$ & 3.6 & & & \\
\hline & FA & 14.2 & 13.0 & 17.0 & $14.8(11.3-21.3)$ & 2.6 & $2.3(-3.2-9.7)$ & 2.6 & 0.000024 \\
\hline
\end{tabular}

Me - median; Q1 - first quartile; Q3 - third quartile; BA - baseline assessment, FA - final assessment. 


\section{Conclusion}

The present study shows that gait and balance in HD patients improved after PNF therapy. PNF is based on the concept of stimulation of the brain in order to employ the compensatory mechanisms and neuronal plasticity to restore the lost function. The efficacy of PNF in HD demonstrates that the brain of a HD person which is globally burdened, may still be successfully stimulated. We suggest that physiotherapy based on the PNF concept should be used in HD as a complementary method to pharmacotherapy because it is safe and efficient.

\section{Conflict of interest}

None declared.

\section{Acknowledgment and financial support}

We wish to confirm that funding source hand no involvement in conduct of the research or preparation of the article.

\section{Ethics}

The work described in this article has been carried out in accordance with The Code of Ethics of the World Medical Association (Declaration of Helsinki) for experiments involving humans; Uniform Requirements for manuscripts submitted to Biomedical journals.

\section{R E F E R E N C E S}

[1] Shang H, Danek A, Landwehrmeyer B, Burgunder JM. Huntington's disease: new aspects on phenotype and genotype. Parkinsonism Relat Disord 2012;18(1):107-9.

[2] Grimbergen YA, Knol MJ, Bloem BR, Kremer BP, Roos RA, Munneke M. Falls and gait disturbances in Huntington's disease. Mov Disord 2008;23(7):970-6.

[3] Berg KO, Wood-Dauphinee SL, Williams JI, Maki B. Measuring balance in the elderly: validation of an instrument. Can J Public Health 1992;83:7-11.

[4] Delval A, Krystkowiak P, Blatt JL, Labyt E, Dujardin K, Destée A, et al. Role of hypokinesia and bradykinesia in gait disturbances in Huntington's disease: a biomechanical study. J Neurol 2006;253:73-80.

[5] Churchyard A, Morris M, Georgiou N, Chiu E, Cooper R, Iansek R. Gait dysfunction in Huntington's Disease: parkinsonism and a disorder of timing. Adv Neurol 2001;87:375-85.

[6] Koller W, Trimble J. The gait abnormality of Huntington's disease. Neurology 1985;35:1450-4.

[7] Tian J, Herdman J, Zee S, Folstein E. Postural stability in patients with Huntington's disease. Neurology 1992;42(6):1232-8.

[8] Hausdorff JM, Cudkowicz ME, Firtion R, Wei JY, Goldberger AL. Gait variability and basal ganglia disorders: stride-tostride variations of gait cycle timing in Parkinson's disease and Huntington's disease. Mov Disord 1998;13(3):428-37.

[9] Khalil H, Quinn L, van Deursen R, Dawes H, Playle R, Rosser A, et al. What effect does a structured home-based exercise programme have on people with Huntington's disease? Clin Rehabil 2013;27(7):646-58.

[10] Zinzi P, Salmaso D, De Grandis R, Graziani G, Maceroni S, Bentivoglio A, et al. Effects of an intensive rehabilitation programme on patients with Huntington's disease: a pilot study. Clin Rehabil 2007;21:603-13.

[11] Bohlen S, Ekwall C, Hellström K, Vesterlin H, Björnefur M, Wiklund L, et al. Physical therapy in Huntington's disease toward objective assessments? Eur J Neurol 2013;20(2):389-93.

[12] Nance MA. Comprehensive care in Huntington's disease, a physician's perspective. Brain Res Bull 2007;72:175-8.

[13] Mestre TA, Ferreira JJ. An evidence-based approach in the treatment of Huntington's disease. Parkinsonism Relat Disord 2012;18(4):316-20.

[14] Adler S, Beckers D, Buck M. PNF in practice: an illustrated guide. 3rd ed. Germany: Springer; 2008.

[15] Mirek E, Chwała W, Laska J, Szczudlik A, Rudzińska M. Patterns of locomotion in patients with Parkinson's disease after PNF method of therapeutic rehabilitation. Gait Posture 2004;20:61-112.

[16] Palanikumar G, Parikh SR. Effect of proprioceptive neuromuscular techniques (PNF) in balance and gait of Parkinson's patients. Mov Disord 2012;27(1):925.

[17] Shoulson I, Fahn S. Huntington disease: clinical care and evaluation. Neurology 1979;29:1-3.

[18] Bohannon RW, Andrews AW, Thomas MW. Walking speed: reference values and correlates for older adults. J Orthop Sports Phys Ther 1996;24(2):86-90.

[19] Ueshima K, Kamata J, Shibusawa M. Evaluation of exercise performance by $20 \mathrm{~m}$-walking test before and after cardiac surgery. Cardioangiology 1999;45(4):381-6.

[20] Podsiadło D, Richardson S. The timed "Up and Go": a test of basic functional mobility for frail elderly persons. J Am Geriatr Soc 1991;39:142-8.

[21] Tinetti ME, Williams TF, Mayewski R. Fall risk index for elderly patients based on number of chronic disabilities. Am J Med 1986;80:429-34.

[22] Studentski S, Duncan PW. Functional reach: predictive validity in a sample of elderly male veterans. J Gerontol 1992;47:93-8.

[23] Pastor MA, Day BL, Marsden CD. Vestibular induced postural responses in Parkinson's disease. Brain 1993;116:11-7.

[24] Rao AK, Muratori L, Louis ED. Clinical measurement of mobility and balance impairments in Huntington's disease: validity and responsiveness. Gait Posture 2009;29:433-6.

[25] Busse M, Khali H, Quinn L, Rosser AE. Physical therapy intervention for people with Huntington's disease. Phys Ther 2008;88(7):820-30.

[26] López-Sendón Moreno JL, Palau Fayos JM, Díaz de Santiago A. Neuroleptic malignant syndrome induced by olanzapine in a patient with Huntington's disease. J Huntington's Dis 2012;1(1):31-2.

[27] Vreugdenhil A, Canell J, Davies A, Razay G. A communitybased exercise programme to improve functional ability in people with Alzheimer's disease: a randomized controlled trial. Scand J Caring Sci 2012;26(1):12-9.

[28] Craufurd D, Thompson JC, Snowden JS. Behavioral changes in Huntington disease. Neuropsychiatry Neuropsychol Behav Neurol 2001;14(4):219-26.

[29] Piira A, van Walsem R, Mikalsen G, Nilsen H, Knutsen S, Frich JC. Effects of a one year intensive multidisciplinary rehabilitation program for patients with Huntington's disease: a prospective intervention study. PLOS Curr Huntington Dis 2013;5.

[30] Gobbi LT, Oliveira-Ferreira MD, Caetano MJ, Lirani-Silva E, Barbieri FA, Stella F, et al. Exercise programs improve mobility and balance in people with Parkinson's disease. Parkinsonism Relat Disord 2009;15(December (Suppl. 3)):S49-52. 